\title{
Estimation and Assessment of Total Phosphorus and Trophic State Index Estimated from Landsat 8 Dataset on 2018 at Daecheong Reservoir
}

\author{
Jongjin Baik ${ }^{1 \oplus} \cdot$ Jongmin Park ${ }^{2} \cdot$ Minha Choi ${ }^{3,+\odot}$ \\ ${ }^{1}$ Center for Built Environment, Sungkyunkwan University \\ ${ }^{2}$ Department of Civil and Environmental Engineering, University of Maryland \\ ${ }^{3}$ Graduate School of Water Resources, Sungkyunkwan University
}

(Received July 13, 2020; Revised August 24, 2020; Accepted August 31, 2020)

Objectives: Remote sensing of water quality parameters (WQPs) has been widely applied along with the emerging importance of obtaining the spatial pattern of water quality at inland reservoir. This study retrieved the Total Phosphorus (TP) via remote sensing imagery at Daecheong reservoir and used it for acquiring the spatial distribution of Trophic State Index (TSI).

Methods: First, stepwise regression for TP was established using the ground-based TP measurement and reflectance of Landsat 8 collocated in space and time. With the developed regression model, we estimated the spatial distribution of TSI and evaluated the severity of eutrophication at Daecheong reservoir.

Results and Discussion: The result confirmed that predicted TP yielded reasonable statistics compared against measured TP with $\mathrm{R}^{2}$ of 0.956 and $\mathrm{p}$-value of 0.022 . Seasonal variation of TP was highly influenced by the precipitation. Similarly, precipitation also influenced to the spatial pattern of TSI. Before the rainfall event (e.g., August 22 2018) at Daecheong reservoir, TSI metric indicated the oligotrographic stage. However, TSI of Daecheong reservoir after the rainfall (e.g., October 25 2018) indicated the mesotrophic and eutrophic stage.

Conclusions: These results confirmed that the retrieval of WQP from remote sensing imagery can serve as a robustness tool to monitor the water quality over the large scale area.

Keywords: Water Quality, Satellite, Landsat 8, Daecheong Reservoir

The Korean text of this paper can be translated into multiple languages on the website of http://jksee.or.kr through Google Translator. 


\title{
연구논문
}

\section{Landsat 8 자료를 이용한 2018년 대청호에서의 총인 및 영양상태 평가 지표 추정 및 평가}

백종진 $^{1 \odot} \cdot$ 박종민 $^{2 \odot} \cdot$ 최민하 $^{3,+\odot}$

\author{
'성균관대학교 건설환경연구소 \\ ${ }^{2}$ 메릴랜드대학교 건설환경공학과 \\ ${ }^{3}$ 성균관대학교 수자원전문대학원
}

목적: 호소의 수질에 대한 공간적인 분포 파악의 중요성이 대두됨에 따라서 공간적인 파악이 가능한 원격탐사 기 법이 요구되었다. 본 연구는 대청호에서의 수질인자에 대하여 산정하고 부영양화에 대한 분석을 하기 위하여 영양 상태 평가지수를 파악하였다.

방법: 대청호 측정 지점 중 2018년에 수질인자인 총인(Total Phosphorus, TP)을 관측하는 측정 데이터와 해당 시기 의 Landsat 8 에 대한 광학 영상을 확보하였다. 수집한 자료를 기반으로 Landsat 8 의 밴드와 그 조합을 통해 단계적 다중 선형 회귀 분석(stepwise analysis)을 사용하여 인공위성 기반의 총인에 대한 회귀식을 산정하였다. 이렇게 산 정된 총인에 대한 공간적 분포를 기반으로 Aizaki's TSI를 산정함으로써 대청호의 영양상태를 평가하였다.

결과 및 토의: 추정된 회귀식을 통해서 산정된 인공위성 기반의 $\mathrm{TP}$ 와 지점 기반 $\mathrm{TP}$ 의 통계학적 분석의 결과는 $\mathrm{R}^{2}$ 이 $0.956, \mathrm{p}$-value는 0.022 로 높은 수준의 유의성을 나타내었다. 지점 기반의 수질 측정 데이터의 시계열을 확인하 면, 강우의 영향이 수질에 대한 직접적인 영향을 미치는 것을 확인할 수 있었다. 이러한 영향은 인공위성 기반의 $\mathrm{TSI}$ 의 결과에서도 확인할 수 있다. 인공위성 기반의 TSI의 결과에서 강우가 발생하기 전인 2018년 8 월 22일에는 빈영양상태를 나타내고 있으며, 강우 발생 후에 관측된 2018년 10월 25일의 결과를 확인하면 중영양화 상태와 부 영양 상태로 평가되었다.

결론: 인공위성이 수질 관측에서 호소 내에서의 광역 감시 도구 역할을 할 수 있는 활용성 및 통찰력에 도움이 될 것으로 판단된다.

주제어 : 수질, 인공위성, Landsat 8 , 대청댐

\section{1. 서 론}

기후변화로 인한 영향으로 수자원의 관리에 대한 관심이 증대되고, 수자원의 확보 차원에서 다목적 댐으로 건설된 호소들은 대부분 유속이 느리기 때문에 이로 인해서 하천에 비해 많은 수질환경의 문제가 발생하게 된다. ${ }^{1)}$ 대표적으로 각종 오염원의 증가 및 토지이용도의 증가로 인한 하천으로 의 오염 물질의 유입으로 인해 빠르게 영양염류로 인한 부 영양화와 녹조현상이 빈번히 발생하고 있다. ${ }^{2)}$ 이로 인한 생 태계 교란, 악취, 심미적 요인 등의 환경적 문제가 발생함으 로써 수자원 이용에 심각한 문제로 작용하고 있으며, 이러 한 수자원은 생물의 음용수로 이용되기 때문에 수질관리가 절실한 것으로 보고되고 있다. ${ }^{3)}$ 특히 국내/외에서 부영양화 를 가속시키는 주요인자가 총질소, 총인(TP) 등으로 알려져
있어 많은 선행연구들이 진행되어 왔다.3-7)

국내는 댐 및 다양한 보를 건설하여 정체 수계인 인공호 가 많이 조성되어 있으며 형태가 길고 좁으며 수체의 종적 혼합이 제한되어있다. 따라서 공간적, 계절적 특성을 반영하 여 수질에 대한 분석이 필요하지만, 넓은 호소의 영양 상태 를 체계적으로 모니터링하기에는 재정적, 인력적 문제가 있 으며, 시료 채취 및 검사 등에 대한 시간적 소비가 많이 소 요되며, 넓은 지역에 대한 장기 관측을 충족하기가 어렵다. ${ }^{8)}$

과학 기술의 발전에 따라 인공위성을 활용한 다양한 분 야에 적용되어 왔다.9) 인공위성의 초분광 센서는 지표에서 의 생/물리학화적 특성이 관측 가능하며, 지표물의 대상체 에 대한 질적, 양적 정보의 획득이 가능하다. 지점 자료만을 이용한 수질 측정은 지점 자료 주변의 수질만을 측정하고 그 자료를 이용한 전체 수질을 대표하는 것은 정밀한 수질 
오염의 심화 지역 분석에 한계를 가지고 있다. 광역적 범위 에서의 관측이 가능한 인공위성을 사용함으로써 현지 관측 에서의 제한 및 한계점을 해결함으로써 공간적인 정량적 데 이터베이스의 가시화를 통하여 고도화된 수질 환경조사 및 평가를 할 수 있다. 이러한 인공위성 센서의 특성을 기반으 로 인공위성의 자료의 활용 가치 및 사용이 활성화되면서 국외/국내에서 해수 및 수역에서 인공위성 센서의 광학적 스펙트럼 특성을 이용하여 수표면의 반사도와의 관계를 이 용하여 오염물질의 분포현황 및 이동상태를 파악하는 연구 가 활발히 진행되어왔다. 인공위성을 이용한 수질인자에 대 한 영향만을 고려한 연구가 대부분 이뤄졌으며, 근래에 들 어서 녹조에 대한 영향을 파악하기 위한 영양염류 및 영양 상태 평가지수(Trophic State Index, TSI)에 대한 선행연구들 이 이뤄지고 있다. ${ }^{7,10-15)}$

연구대상지역으로 금강에 위치한 대청댐으로 생긴 대 청호는 댐 건설로 인하여 물의 흐름이 느려지고 물의 체류 시간이 증가함에 따라서 많은 수질 문제가 발생하고 있다. 따라서, 많은 지점 관측을 실시하고 있으나 유입하천 및 대청호에서의 공간적인 수질변화에 대한 조사가 필요하다 는 주장이 언급되어왔다. 본 연구에서는 원격탐사 위성인 Landsat 8 을 활용하여 대청댐에서의 $\mathrm{TP}$ 에 대한 공간적인
수질에 대해서 산정해보고자 하였다. 또한, 녹조의 발생 영 향을 나타낼 수 있는 영양상태 평가지수에 대해서 산정함으 로써 인공위성 자료를 활용한 2018년도에 대한 공간적인 평가를 실시하였다.

\section{2. 연구지역, 데이터, 및 방법론}

\section{1. 연구지역}

본 논문의 연구지역으로는 대한민국 4대강 중 하나인 금 강 수계를 기준으로 연구를 실시하였다. 금강은 크고 작은 약 20 개 지류가 본류로 합류하는데 금강의 주요 지류는 논산천, 미호천, 갑천, 강경천 등이 있으며, 대한민국에서 소양호와 충주호에 이어 세 번째로 큰 호수인 대청호가 위치해있다. 금강 수계는 호남 및 충청도민들의 주요 식수로 쓰일 뿐만 아 니라 산업, 농업, 생활용수로 이용되고 있다. 또한, 대청댐은 금강 하류의 홍수조절 및 수력발전에 이용되고 있다. ${ }^{16-17)}$

본 연구에서는 2018년에 대한 총인(total phosphorus, TP $[\mathrm{mg} / \mathrm{L}])$ 에 대해서 인공위성 자료의 상관성 분석 및 회귀식 을 적용하기 위하여 대청댐 내에서의 관측 지점인 4곳(현 도, 대청, 대청댐, 대청댐1)을 선정하였다(Fig.1, Table1)(물 환경정보시스템, http://water.nier.go.kr/).

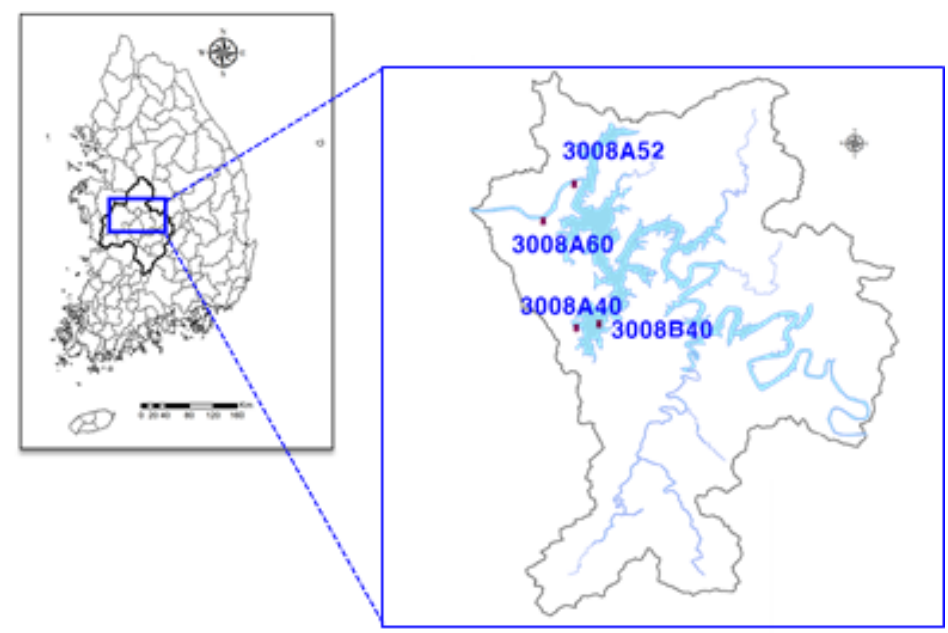

Fig. 1. Geographical information of measurement sites in Daecheong Reservoir.

Table 1. Summary of information of the water quality measurement.

\begin{tabular}{|c|c|c|c|}
\hline $\begin{array}{c}\text { Site name } \\
\text { (Site number) }\end{array}$ & Location & Measured parameter & Installation year \\
\hline $\begin{array}{l}\text { Hyeondo } \\
(3008 \mathrm{~A} 60)\end{array}$ & Seokbong, Daedeok-gu, Daejeon, Republic of Korea & \multirow{4}{*}{$\begin{array}{c}\text { Water temperature, } \\
\text { Dissolved Oxygen (DO), } \\
\text { Biochemical Oxygen Demand (BOD), } \\
\text { Chemical Oxygen Demand (COD), } \\
\text { Suspended Solid (SS), } \\
\text { Total Nitrogen (TN), } \\
\text { Total Phosphors (TP), } \\
\text { Total Organic Carbon (TOC) }\end{array}$} & 1989 \\
\hline $\begin{array}{l}\text { Daecheong Dam } \\
\quad(3008 \text { A40) }\end{array}$ & $\begin{array}{c}\text { (Chudong intake tower) Chudong, Daedeok-gu, Daejeon, } \\
\text { Republic of Korea }\end{array}$ & & 1990 \\
\hline $\begin{array}{l}\text { Daecheong } \\
\text { (3008A52) }\end{array}$ & $\begin{array}{l}\text { (Daecheon-bridge) Haseok-ri, Hyeondo-myeon, Cheongju-si, } \\
\text { Chungcheongbuk-do, Republic of Korea }\end{array}$ & & 2008 \\
\hline $\begin{array}{c}\text { Daecheong Dam } 1 \\
\text { (3008B40) }\end{array}$ & Chudong, Daedeok-gu, Daejeon, Republic of Korea & & 1992 \\
\hline
\end{tabular}


Table 2. Information of bands from the Landsat 8 (https://landsat.gsfc.nasa.gov/landsat-8/).

\begin{tabular}{|c|c|c|c|c|}
\hline \multicolumn{5}{|c|}{ Landsat 8} \\
\hline Band & & Wavelength (Description) & Resolution & Useful for mapping \\
\hline 1 & & $\begin{array}{l}0.433 \text { to } 0.453 \mu \mathrm{m} \\
\text { (Coastal / Aerosol) }\end{array}$ & & Coastal and aerosol studies \\
\hline 2 & & $\begin{array}{l}0.450 \text { to } 0.515 \mu \mathrm{m} \\
\quad \text { (Visible blue) }\end{array}$ & & $\begin{array}{c}\text { Bathymetric mapping, distinguishing soil from vegetation and } \\
\text { deciduous from coniferous vegetation }\end{array}$ \\
\hline 3 & Visible & $\begin{array}{l}0.525 \text { to } 0.600 \mu \mathrm{m} \\
\text { (Visible green) }\end{array}$ & & $\begin{array}{c}\text { Emphasizes peak vegetation, which is useful for assessing plant } \\
\text { vigor }\end{array}$ \\
\hline 4 & & $\begin{array}{l}0.630 \text { to } 0.680 \mu \mathrm{m} \\
\quad \text { (Visible red) }\end{array}$ & $30 \mathrm{~m}$ & Discriminates vegetation slopes \\
\hline 5 & & $\begin{array}{l}0.845 \text { to } 0.885 \mu \mathrm{m} \\
\text { (Near-infrared) }\end{array}$ & & Emphasizes biomass content and shorelines \\
\hline 6 & Infrared & $\begin{array}{l}1.56 \text { to } 1.66 \mu \mathrm{m} \\
\text { (Short wavelength infrared) }\end{array}$ & & $\begin{array}{c}\text { Discriminates moisture content of soil and vegetation; } \\
\text { penetrates thin clouds }\end{array}$ \\
\hline 7 & & $\begin{array}{l}2.10 \text { to } 2.30 \mu \mathrm{m} \\
\text { (Short wavelength infrared) }\end{array}$ & & $\begin{array}{l}\text { Improved moisture content of soil and vegetation; penetrates } \\
\text { thin clouds }\end{array}$ \\
\hline
\end{tabular}

\subsection{Landsat 8}

본 연구에서 수질 관측 및 분석을 위하여 Landsat 8 인공 위성 자료(LC08-L1TP)를 이용하여 연구를 실시하였다. 이 위성은 Landsat Series 중에서 2013년 2월 11일에 발사되어 가장 최근에 많은 연구에 활용되고 있으며, 가시광역의 공간 해상도는 $30 \mathrm{~m}$ 를 가지고 있으며, 열적외선(Thermal Infrared, TIRS) 밴드의 경우에는 기존의 공간해상도에 비하여 100 $\mathrm{m}$ 공간해상도를 가지고 있다. 본 연구에서 정밀도 및 지형 보정이 이뤄진 Level-1 Precision Terrain (L1TP) 자료 중 시 계열 분석에 적합한 것으로 알려진 Tier 1 (T1) 자료를 활 용하여 연구에 적용하였다(https://glovis.usgs.gov/). 연구에 사용된 밴드는 1 에서 7 번 밴드로 Landsat 8 에 대한 정보는

Table 2에 정리하였다.

연구기간으로는 2018년까지 기간 동안 촬영된 영상자료 중 구름의 양이 $10 \%$ 미만인 날짜만을 대상으로 하여 연구 에 적용하였다. 연구에서 2018년(1월 10일, 4월 16일, 11월 26일)에 물환경정보시스템에서 현도, 대청댐, 대청댐 1 , 대청 에서 관측된 자료를 통한 관계식을 산출하였으며, 이 관계 식을 실시간수질정보시스템에서 관측된 지점에 적용하여 검증을 실시하는 연구를 진행하였다. 본 연구에서 관계식을 나타내기 위하여 인공위성 이미지 자료로 제공되는 $\mathrm{DN}$ (Digital number)를 전처리 작업을 통해서 반사도 값으로 변 화하여 사용하였다(Eq. (1), (2)).

$$
\begin{aligned}
& \rho_{\lambda^{\prime}}=M_{\rho} \times D N+A_{\rho} \\
& \rho_{\lambda}=\frac{\rho_{\lambda^{\prime}}}{\sin \left(\theta_{S E}\right)}=\frac{\rho_{\lambda^{\prime}}}{\cos \left(\theta_{S Z}\right)}
\end{aligned}
$$

여기서, 여기서 $\rho_{\lambda^{\prime}}$ 는 태양각 보정전의 밴드별 반사도 값 이고 $\mathrm{DN}$ 은 영상에서의 각 밴드별 화소값이며, $A_{\rho}$ 와 $M_{\rho}$ 는
밴드별 고유 반사도 가산 환산 계수와 배수 환산 계수를 나타낸다. $\rho_{\lambda}$ 는 태양각 보정후의 반사도를 나타내며 $\theta_{S E}$ 와 $\theta_{S Z}$ 지역 태양 고도각과 지역 태양천정각 $\left(\theta_{S Z}=90^{\circ}-\theta_{S E}\right)$ 을 나타낸다. 각 밴드별 정보는 인공위성 자료와 같이 제공되 는 메타 정보를 통해서 확인할 수 있다.

\subsection{Multiple Linear Regression}

본 연구에서는 Multiple Linear Regression (MLR)을 사용 하여 종속 변수인 수질 자료와 여러 독립적인 설명 변수 (Landsat 8 밴드) 사이의 관계성을 통하여 모형을 구축하였 습니다. 연구 지역에서의 수질 매개변수와 Landsat 8 자료 사이의 관계를 파악하기 위하여 단계적 다중 회귀가 사용 된다.

$$
W Q P=A_{0}+\sum_{i=1}^{k}\left(A_{i} \times L 8_{i}\right)
$$

여기서, water quality parameters (WQP)는 수질 매개 변수 (TP)을 나타내며, L8는 Landsat 8 의 각 밴드의 reflectance와 조합을 나타냅니다. $\mathrm{k}$ 는 Landsat 8 밴드 및 밴드 조합 번호 를 나타내며, $\mathrm{A}_{0}$ 과 $\mathrm{A}_{\mathrm{i}}$ 는 관측 값을 사용하여 도출된 경험적 회귀 계수이다. $\mathrm{WQP}$ 와 스펙트럼 특성 사이의 관계에 대한 이전 연구들을 방법을 바탕으로, 이 연구에서 통계 분석을 위해 인공위성의 visible, infrared 밴드들의 각 밴드와 밴드 비를 활용하여 영양염류에 관한 최적 회귀식을 산정하여 연 구를 진행하였다.

\section{4. 영영상태 평가지표(Trophic State Index, TSI)}

호수 및 하천 수질의 영양등급을 구분하기 위해 항목별 단위 기준 또는 계량된 무단위 기반의 영양상태 평가지표가 
Table 3. Information of classification of TSI.

\begin{tabular}{cc} 
TSI & Classification of TSI \\
$20 \leq \mathrm{TSI} \leq 44$ & Ultra-oligotrophic \\
$45 \leq \mathrm{TSI} \leq 52$ & Oligotrophic \\
$53 \leq \mathrm{TSI} \leq 70$ & Mesotrophic \\
$\mathrm{TS} \mid>70$ & Eutrophic \\
\hline
\end{tabular}

개발되어왔다. 투명도, Chl-a, TP와 같은 수질 판별 인자들 을 통하여 호소의 영양상태를 파악하기 위해 Carlson ${ }^{18)}$ 에 의해서 TSI가 제안되었으며, 기존의 TSI 방법이 투명도를 기준으로 한 방법이라면 클로로필 농도를 기준으로 한 부영 양화 지수를 산정하는 Aizaki ${ }^{19)}$ 제시하였으며, 부영양화와 밀접한 관계를 가진 수질 특성의 어느 한 항목만 측정하여 도 영양상태를 파악할 수 있도록 하였다. 영양상태 지수는 아래 식을 통해서 산정할 수 있으며, 부영양화도는 Table 3 과 같이 나타낼 수 있다.

$$
T S I_{(T P)}=10 \times\left(2.46+\frac{6.71+1.15 \times \ln (T P)}{\ln 2.5}\right)
$$

\section{3. 결과 및 고찰}

\subsection{Regression Analysis}

일반적으로 영양염류인 $\mathrm{TN}, \mathrm{TP}$ 는 하천 및 호수에서의 부 영양화를 발생시키며 조류를 번식하는 영양성분이 된다. 선 행연구에서 인공위성을 이용한 다양한 스펙트럼 대역 사이 의 비를 이용하여 지상기반의 수질 측정값과 원격탐사 자료 와의 경험적 관계를 통해 정량화하였다. 선행연구들에서도 확인할 수 있듯이, 다양한 시각 스펙트럼 대역 사이의 비(녹 색과 빨간색 사이의 비율, 청색과 적색의 비, 적외선과 적색 사이의 비율 등)가 $\mathrm{TP}$ 의 정량화하기 위하여 사용된다. ${ }^{20-21)}$ 경험적 관계에 대한 경험식 산출에 앞서 먼저 지상 관측 수 질 자료와 Table2에 표기된 Landsat 8 의 1번부터 7번 밴드 (Visible과 Near Infrared 영역)와 각 밴드 조합의 상관관계 를 파악해 보았다(Table 4). 먼저, 가시광선과 근적외선영역 에서는 수질과의 관계성이 있는 반면에 단파장 적외선 영역 에서는 TP의 상관성이 확연하게 낮은 것을 확인할 수 있다. 따라서 Landsat 8 을 이용한 수질에 대한 분석에서 단파장
적외선 영역(B6과 B7)을 포함한 조합은 제외하였다. TP의 대한 결과를 확인하면, B5, B4, B3와의 관계성이 -0.65의 음 의 관계를 보이고 있다. 상대적으로, 다른 밴드에 비하여, $\mathrm{B} 1, \mathrm{~B} 6, \mathrm{~B} 7$ 밴드에 대한 상관성이 떨어져서 밴드 조합에서 도 제외하였다.

\subsection{Estimation of the TP using the Regression Model}

본 연구에서 Table3에 나타나있는 Landsat 8의 반사도 및 밴드 조합과 수질 인자인 $\mathrm{TP}$ 를 이용하여 단계별 다중 회귀 분석(stepwise multiple regression) 방법을 이용한 다중회귀 분석을 실시하였으며, 이 식을 이용하여 수질인자를 산정하 는 회귀모형을 실시하였다. Stepwise는 다른 독립변수가 회 귀식에 존재할 때 종속변수에 영향력이 있는 변수만을 고려 하는 방법으로 Table 4에 나타나있는 변수 중 유의수준 0.05 (p-value $\leq 0.05)$ 이내에서 선별된 변수를 포함하도록 하였 다. 추정된 $\mathrm{TP}$ 식은 단일밴드와 밴드비율(B5, B4, B3, B2)조 합의 다중회귀 모형으로 표현되었다.

$$
\begin{aligned}
T P=0.140+ & 0.148 \times B 5+0.009 \times \frac{B 5}{B 4} \\
+ & \left(-0.089 \times \frac{B 4}{B 3}\right)+\left(-0.1 \times \frac{B 3}{B 2}\right)
\end{aligned}
$$

여기서, B는 Landsat 8 위성 영상자료의 band를 나타내며, 각 숫자들은 밴드 번호를 나타내고 있다.

Fig. 2는 Eq (5)의 회귀식을 통해서 인공위성 영상자료를

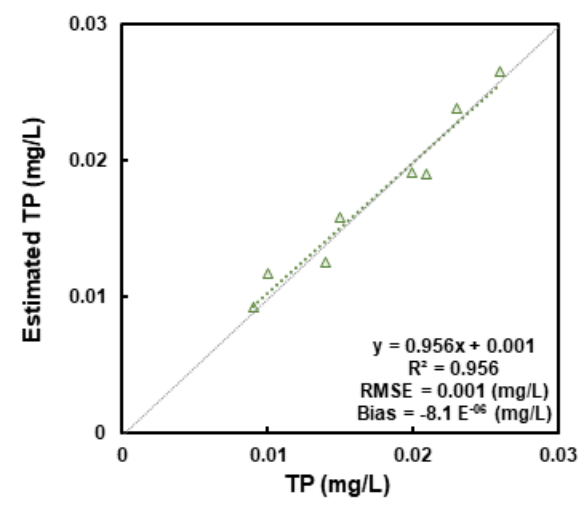

Fig. 2. Scatter plot of measured TP and estimated TP from Landsat 8.

Table 4. Result of Person's correlation of TP with Landsat 8 bands and band combinations.

\begin{tabular}{ccccccccccc}
\hline WQP & B1 & B2 & B3 & B4 & B5 & B6 & B7 & B2/B3 & B2/B4 \\
\hline TP & -0.566 & -0.621 & -0.697 & -0.684 & -0.664 & -0.214 & -0.354 & 0.846 & 0.815 \\
\hline WQP & B2/B5 & B3/B4 & B3/B5 & B4/B5 & B3/B2 & B4/B2 & B5/B2 & B5/B3 & B5/B4 \\
\hline TP & 0.636 & 0.646 & 0.557 & 0.460 & -0.841 & -0.800 & -0.503 & -0.377 & -0.237 \\
WQP & B4/B3 & & & & & & & \\
\hline TP & -0.666 & & & & & & & \\
\hline
\end{tabular}




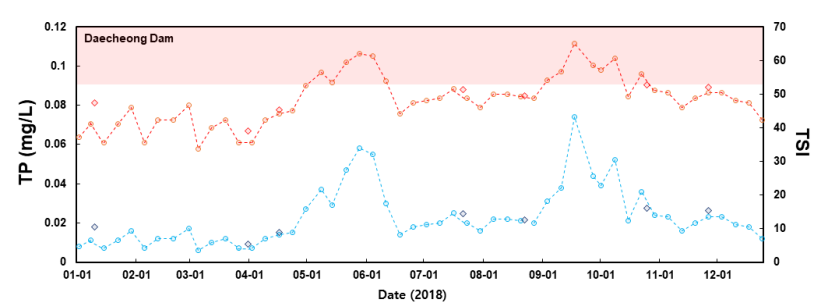

a) Daecheong Dam

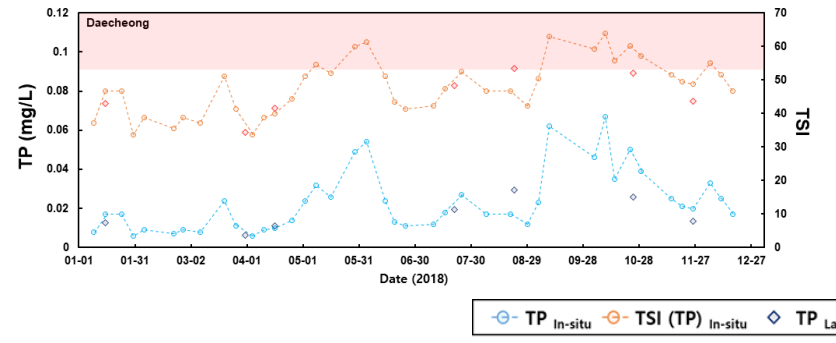

c) Daecheong

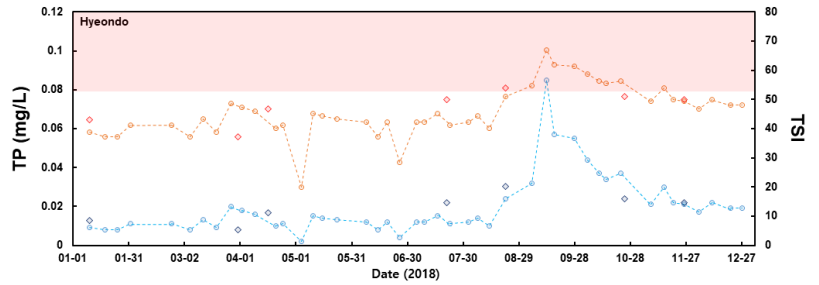

b) Hyeondo

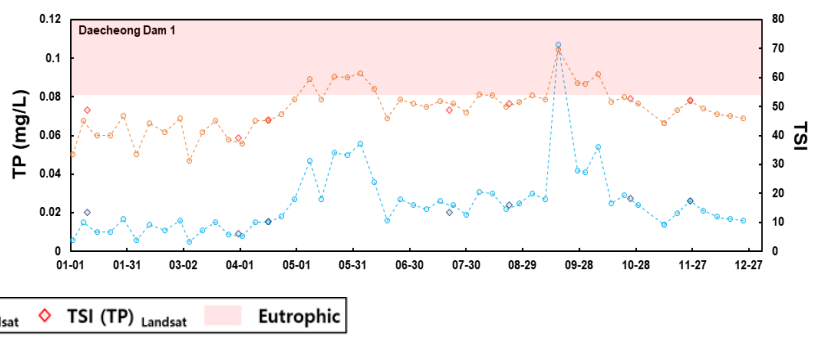

d) Daecheong Dam 1

Fig. 3. Time series for in-situ and Landsat 8 based TP and TSI (TP) on study sites.

이용한 $\mathrm{TP}$ 의 예측치와 지상 관측 $\mathrm{TP}$ 의 분포도를 나타낸 것 이다. 단일밴드와 밴드비를 이용한 다중회귀식을 적용한 예 측값과 실측값의 결과는 $1: 1$ 선에 거의 근접하게 일치하는 경향을 보였으며, 통계학적 결과를 확인하면 $\mathrm{R}^{2}$ 는 0.956 , $\mathrm{p}$-value는 0.022 로 높은 수준의 유의성을 보였고, 평균제곱 근편차(root mean square error, RMSE)는 $0.001 \mathrm{mg} / \mathrm{L}$ 를 나 타내었다.

\subsection{Spatial Distributions of TP and TSI (TP)}

Fig.3은 2018년에 대해서 대청호 관측 지점과 인공위성으 로부터 산정된 TP와 TSI의 결과를 나타내었다. 먼저, 지점 기반의 경향을 확인하면, 4 월 말부터 $\mathrm{TP}$ 의 농도가 증가되었 다가 6월에 다시 감소하였으며 8월에는 매우 높은 $\mathrm{TP}$ 의 증 가를 나타내었다가 10 월 중순에 다시 평균적인 경향을 나타 내었다. 특히 이 시기에 Aizaki가 제안한 TSI (TP)를 계산한 결과 동일한 시기에 부영양화의 상태를 나타내는 것으로 볼 수 있으며, 전반적으로 인공호인 특성을 가지는 대청호가 2018년도에 평균적으로 1월에서 4월 초를 제외하고는 중영 양(Mesotrophic) 상태가 유지되는 경향을 나타내었다(Fig. 3). 회귀식을 이용하여 인공위성으로부터 산정된 TP와 이를 이용한 TSI결과(1월 10일, 3월 31일, 4월 16일, 7월 21일, 8 월 22일, 10 월 25일, 11 월 26일)를 실제 관측지점과 비교하 였다(Fig. 3). 호소 내에 존재하는 대청댐1과 대청댐 지점의 경우 전반적으로 모든 기간에 대해서 경향을 잘 나타내고 있는 것을 확인할 수 있었으나, 댐 유출구 지역인 현호와 대 청 지점의 경우 다른 지점의 비해 과대 및 과소 산정되는 경향이 나타내고 있다. 이는 정제된 호소인 대청댐1과 대청 댐과는 다르게 하천에 설치되어 있는 두 지점의 $\mathrm{TP}$ 의 정확 한 관측 시간과 인공위성의 관측 시간의 불일치로 인한 문 제로 보여진다. 이는 댐의 방류 등 외부적인 요인으로 인하
여 하천의 수질인자의 변동을 회귀식으로 정확하게 판단하 지 못한 것으로 보이며, 또한, 매일 관측되지 않는 수질관측 지점의 값이 인공위성이 관측 날짜의 값을 나타내지 않아 실제적인 갑작스러운 변동성을 나타내지 않아 확실한 수질 의 변동을 나타낼 수 없다. 이를 해결하기 위해서는 하천지 역에서의 연속적인 관측날짜가 제공되는 지점에서의 연구 가 필요할 것으로 사료된다.

다중회귀분석을 통하여 얻어진 회귀식을 적용하여 대청호 에서의 모니터링을 실시하였다. 2018년도에 관측된 Landsat 8 위성 영상자료를 Eq. (5)로 유도된 회귀식을 적용하여 TP의 추정 분포도를 Fig. 4에 나타내었으며, Fig. 5는 Eq. (4)의 Aizaki TSI를 적용하여, 대청호의 영양상태 지수에 대해서 구분하였다. 전반적으로 인공위성 자료를 이용해서 추정된 $\mathrm{TP}$ 의 공간 분포는 계절 및 기상 조건에 따라 증가되었다가 감소되는 경향을 나타내고 있다(Fig.4). TP를 통한 영양상 태 평가지표의 분석을 위해서 2018년 1월과 3월에 관측된 Landsat 8 위성 영상으로 추정된 TSI (TP)의 분포를 확인 하면 빈영양과 중영양상태의 분포양상을 나타내고 있으며 Fig. 3의 대청댐에서의 결과와 비교해보았을 때 적절한 분포 양상을 나타내는 것으로 파악된다. Fig. 3 및 조류예보에 따 르면, 2018년 8월 말(8.23)에서 9월 초(9.4)까지 약 $440 \mathrm{~mm}$ 의 강우가 발생하였으며 이로 인하여 오염물질이 다량 하천 으로 유입되었다고 보고되었다. Fig.3의 시계열의 결과에서 도 8월 말부터 대청댐의 TSI (TP)가 증가되었으며, 10 월 말 에 들어서 감소되는 경향을 나타내었다. Fig.5에서 확인하 면, 강우가 오기 전인 8 월 22일에는 대청호 주변에 대부분 중영양화 상태와 간헐적으로 빈영양상태의 분포를 보였다. 여름철에 강우가 많이 발생하고, 구름 및 외부 영향으로 8 월 말에서 10 월 말까지의 활용가능한 인공위성 자료가 없어 정확하게 감소하는 시공간적 경향을 나타내기는 어려우나, 


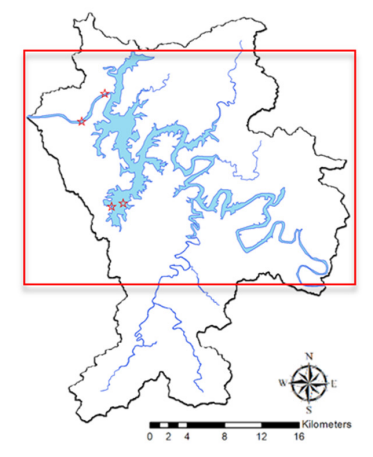

\subsubsection{0}
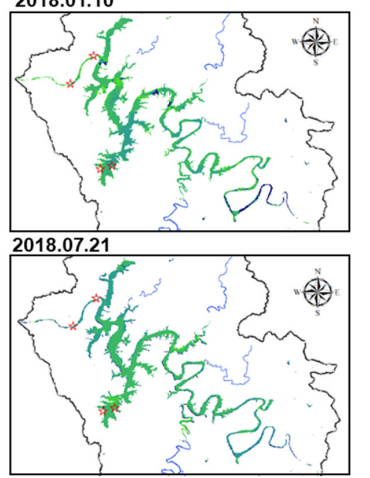

2018.08.22

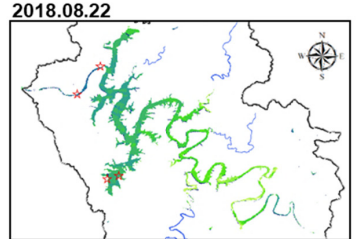

2018.11.26

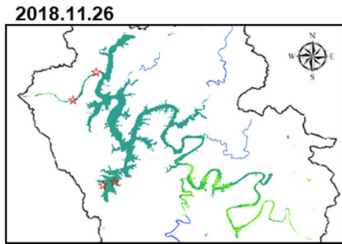

2018.03.31

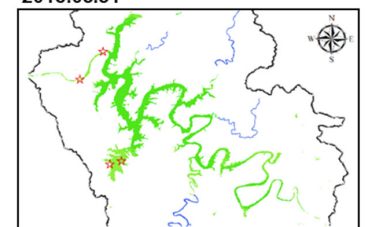

2018.04.16

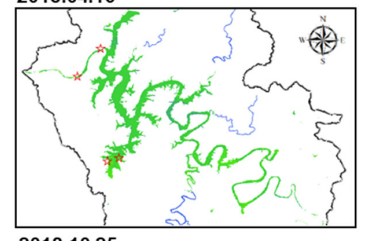

2018.10.25
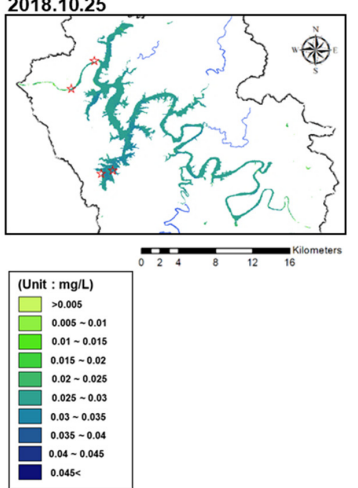

Fig. 4. Spatial distribution map of TP estimated from Landsat 8 in study area.
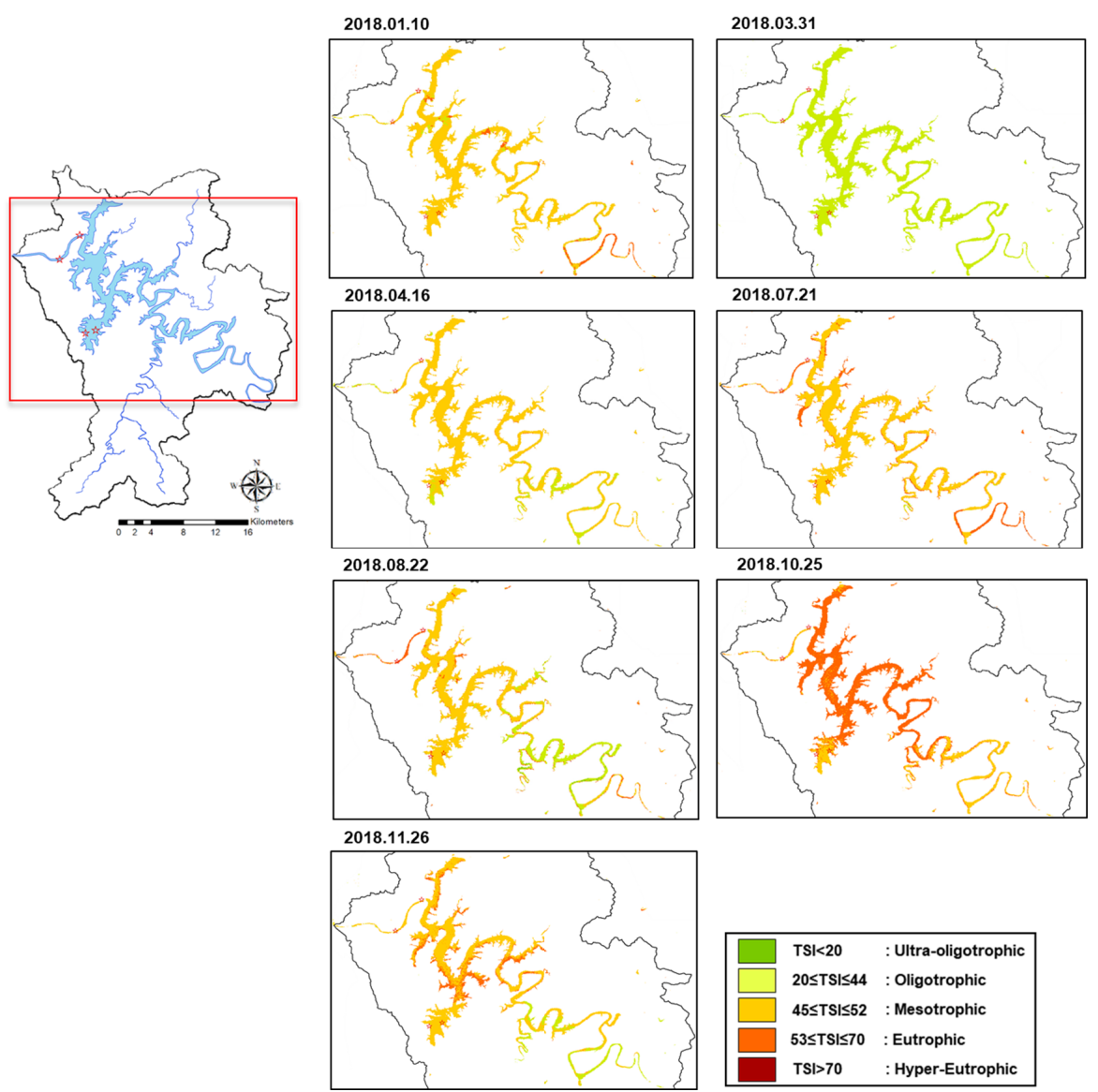

Fig. 5. Distribution mapping of TSI (TP) estimated from Landsat 8 in study area. 
강우로 인한 지표면의 오염물질이 하천으로 유입된 후인 10 월 25 일에 관측된 결과를 보면 시간이 지남에도 불구하고 인공호라는 특성으로 인하여 대청호의 대부분이 부영양화 상태와 중영양화 상태가 혼합되어 있다. 11월 말에 들어서 수온 및 기온이 낮아짐에 따라서 대청호의 주변이 중영양과 빈영양 상태로 변화하는 경향을 나타내었다. 시공간 분석을 통해서 확인한바 계절적 특성에 따른 변동성보다는 강우와 주변환경에 의한 영향이 더 지배적이라고 판단할 수 있다. $\mathrm{TSI}$ 의 공간적 분포를 통하여 잠재적으로 녹조 발생 가능지 역을 영양상태 지수에 대한 분포양상을 시각적으로 확인할 수 있었다.

\section{4. 결 론}

본 연구에서 Landsat 8 위성영상을 이용하여 2018년도의 수질요소를 추정하였고 영양상태 평가지표에 대해서 파악 하였다. 지상 수질 관측 지점 4 개의 자료를 가지고 단계별 다중 회귀분석을 통하여 $\mathrm{TP}$ 에 대한 회귀식을 산정하였으며, 상관결정계수 $\left(\mathrm{R}^{2}\right)$ 는 0.956 으로 산정되었다. 그렇게 산정된 인공위성 기반의 TP 결과를 활용하여 대청호에서의 영양상 태 평가지수를 평가하였다. 평가결과, 전반적으로 1 월에서 3 월 사이에는 빈영양과 중영양 상태가 고르게 분포하는 경 향을 나타내었다. 강우의 영향에 따라 지표면에서의 오염물 질의 유입으로 인해 대청호의 수질이 중영양에서 부영양 상 태로 변화하는 것을 확인할 수 있었다. 전반적으로 인공위 성을 통해 산정된 결과가 공간적인 대표성을 나타낼 수 있 다는 점에서는 활용 가능성이 있다고 할 수 있다. 그러나 본 연구에서도 실제적으로 인공위성과 지상 관측 지점의 관측 시간이 동일한 경우가 매우 드물기 때문에 인공위성과 지상 관측 지점을 모두 활용한 통합적 수질 관리 관측을 위해서 는 인공위성 관측 시간과 지상 측정 시간의 동일화를 가질 필요가 있으며 또한, 지상 기반 반사도 관측 기기의 설치 등 다양한 개선 방안이 필요할 것으로 보인다.

영양상태 평가지표 및 수질 요소를 대표하는데 지점 자료 만을 이용하여 호소 내에서의 수질의 대표성을 나타내기에 는 부족할 수 있다. 따라서 인공위성 자료를 활용한 공간분 포를 산정함으로써 면적 및 측정하지 않는 곳에서의 조류 발생 가능 영역에 대해서 파악할 수 있다는 장점을 가지고 있다. 그러나 인공위성 자료는 고유의 센서 특성으로 인한 외부적인 기상요건에 따른 시간적 연속성 부재 및 대표성 있는 공간해상도의 문제가 있어 연속적 공간적 분포의 수질 /영양상태 평가지표를 산정하기 위해서는 다양한 위성들을 같이 활용하는 방안이 마련되어야 할 것으로 보인다. 결론 적으로 인공호와 같이 물이 정체되어있는 곳에서는 원격탐 사 기법들 중 드론 및 인공위성에 탑재된 센서의 특성을 활 용함으로써 공간적인 수질 환경 변동성을 파악하는데 유용
할 것으로 사료된다.

\section{Acknowledgements}

본 연구는 2018년도 정부(교육부)의 재원으로 한국연구재단 의 지원을 받아 수행된 기초연구사업(NRF-2018R1D1A1B0 7049029)에 의해 수행되었습니다. 이 논문은 2019년도 정부 (과학기술정보통신부)의 재원으로 한국연구재단의 지원을 받 아 수행된 연구(NRF-2019R1A2B5B01070196)입니다.

\section{References}

1. S. C. Back, J. K. Park, J. H. Park, Spatial distribution mapping of cyanobacteria in Daecheong reservoir using the satellite imagery, J. Korean Soc. Agric. Eng., 58(2), 53-63(2016).

2. M. G. Suh, S. H. Lee, J. H. Suh, Study of the trophic state assessment and analysis of water quality improvement by dredging in Hwoiya reservoir, J. Korea Acad.-Industr. Coop. Soc., 15(11), 6943-6951(2014).

3. H. H. Kwon, K. G. An, Trophic State Index (TSI), spatial gradient characteristics and the empirical models for eutrophication evaluations in Daecheong reservoir, J. Environ. Sci. Int., 23(9), 1537-1549(2014).

4. W. He, S. Chen, X. Liu, J. Chen, Water quality monitoring in a slightly-polluted inland water body through remote sensing - case study of the Guanting reservoir in Beijing, China, Front. Environ. Sci. Eng. China, 2(2), 163-171(2008).

5. A. Kumar, Sk. Md. Equeenuddin, D. R. Mishra, B. C. Acharya, Remote monitoring of sediment dynamics in a coastal lagoon: long-term spatio-temporal variability of suspended sediment in Chilika, Estuarine, Coastal Shelf Sci., 170, 155-172(2016).

6. P. P. Patra, S. K. Dubey, R. K. Trivedi, S. K. Sahu, S. K, Rout, Estimation of chlorophyll a concentration and trophic states in Nalban Lake of East Kolkata Wetland, India from Landsat 8 OLI data, Spat. Inf. Res., 25(1), 75-87(2017).

7. D. Kong, B. Kim, Suggestion for trophic state index of Korean lakes (Upper Layer), J. Korean Soc. Water Environ., 35(4), 340-351(2019).

8. J. Lim, J. Baik, H. Kim, M. Choi, Estimation of water quality using Landsat 8 images for Geum-river, Korea, J. Korea Water Resour. Assoc., 48(2), 79-90(2015).

9. H. D. Chun, C. W. Kim, S. W. Ham, K. R. Baek, K. S. Ko, C. G. Kim, Application of remote sensing technology to the survey of ambient $\mathrm{SO}_{2}$ concentrations in wide area, J. Korean Soc. Environ. Eng., 13(4), 285-291(1991).

10. D. Gurlin, A. A. Gitelson, W. J. Moses, Remote estimation of chl-a concentration in turbid productive waters - Return to a simple two-band NIR-red model?, Remote Sens. Environ., 115(12), 3479-3490(2011).

11. K. Song, Z. Wang, J. Blackwell, B. Zhang, F. Li, Y. Zhang, G. Jiang, Water quality monitoring using Landsat Themate Mapper data with empirical algorithms in Chagan Lake, 
China, J. Appl. Remote Sens., 5(1), 053506(2011).

12. G. Wu, L. Cui, L. Liu, F. Chen, T. Fei, Y. Liu, Statistical model development and estimation of suspended particulate matter concentrations with Landsat 8 OLI images of Dongting Lake, China, Int. J. Remote Sens., 36(1), 343-360(2015).

13. C. Giardino, M. Bresciani, I. Cazzaniga, K. Schenk, P. Rieger, F. Braga, E. Matta, V. E. Brando, Evaluation of multi-resolution satellite sensors for assessing water quality and bottom depth of Lake Garda, Sensors, 14(12), 24116-24131(2014).

14. Q. Chen, M. Huang, X. Tang, Eutrophication assessment of seasonal urban lakes in China Yangtze River Basin using Landsat 8-derived Forel-Ule index: a six-year (2013-2018) observation, Sci. Total Environ., 135392(2019).

15. S. K. Jally, A. K. Mishra, S. Balabantaray, Estimation of trophic state index of chilika Lake using Landsat-8 OLI and LISS-III satellite data, Geocarto Int., 35(7), 759-780(2020).

16. Y. S. Lee, K. S. Lee, Organic sediment distribution and release characteristics on lake Daechung, J. Korean Soc. Environ. Eng., 26(6), 665-669(2004).

17. K. H. Oh, Y. C. Cho, Evaluation of contamination level of the sediments from Chusori and Chudong areas in Daechung reservoir, J. Korean Soc. Environ. Eng., 37(5), 277-284(2015).

18. R. E. Carlson, A trophic state index for lakes, Limnol. Oceanogr., 22(2), 361-369(1977).

19. M. Aizaki, A. Ostuki, T. Fukushima, T. Kawai, M. Hosomi, K. Muraoka, Application of modified Carlson's trophic state index to Japanese and its relationship to other parameters related to trophic stage, Res. Rep. Natl. Inst. Environ. Stud., 23, 12-31(1981).

20. F. L. Hellweger, P. Schlosser, U. Lall, J. K. Weissel, Use of satellite imagery for water quality studies in New York Harbor, Estuarine, Coastal Shelf Sci., 61(3), 437-448(2004).

21. G. Mancino, A. Nolè, V. Urbano, M. Amato, A. Ferrara, Assessing water quality by remote sensing in small lakes: the case study of Monticchio lakes in southern Italy, iForest-Biogeosciences and Forestry, 2(4), 154-161(2009).

\section{Authors}

\section{Jongjin Baik}

Center for Built Environment, Sungkyunkwan University, Researcher, ORCID(10 0000-0002-1262-9290

\section{Jongmin Park}

Department of Civil and Environmental Engineering, University of Maryland, Ph.D. Candidate, ORCID(D) 0000-0002-7110-4881

\section{Minha Choi}

Graduate School of Water Resources, Sungkyunkwan University, Professor, ORCID 두 0000-0002-1900-9780 